\section{THE STÄLLDALEN METEORITE}

I $N$ the Scandinavian North, so extraordinarily rich in mines and quarries, there have been found during the last few years a number of new minerals, by which many a mine and even many an inconsiderable opening scarce known in its own parish has become world-famous in mineralogical literature. Several of these findls are of great interest in a systematic aspect-for instance, the discovery of barytite, a new, exceedingly basic variety of felspar containing baryta; of ganomaitite, ihe first natural silicate of lead which has been discovered; of ekdennite, a new mincral containing antimonic acid, from the mines of Langban; and of homilite, a new, beautifully crystallised silicate of boron, containing water, from Brevig. Others again give us a highly unexpected insight into the nature of the chemical forces which are in activity in the interior of the earth-for instance, the Werm. land ruinexals, manganosite, or protoxide of manganese, and pyoktrice, or hydrated protoxide of manganese, which afford evidence of a powerful reducing action. 'The latter mineral has fiuring last year been found at a new locality - the mines of Nordmark.

Iowever important these newly-discovered minerals may be, they do not awaken so keen an interest as the stones which from time to time fall from the heavens, and afford us specimens of the matter to be found in spaces so remote that rays of light require thousands of years to reach them. A new and highly instructive contribution to our knowledge of meteorites has been obtained in Sweden through the fall of the meteorite, which took place at Ställdalen, near Nya Kopparberg, in Orebro liin, on June 28 , 1876 , at I ' 50 A.M., from a fireball which was visible over a large part of middle $S$ weden. In the neighbourhood of Stockholm the meteor appeared as an indistinctlydefined fireball, followed by a long streak of fre. The ball was first visible below the zenith in the north-east or north-north-east, and went from hence towards the horizon in the west, where it generally appeared to fall in the immediate neighbourhood of the spectator, sometimes with, sometimes without, the throwing out of sparks. In the town of Gefle the fire-red ball, followed by a streak of the same colour, was seen moving from north-east to south-west. At the neighbourin:s promontory, Harnis, it was first seen of the size of a large star, speedily increasing, however, leaving a long streak of fire behind it, and finally disappearing without noise, falling, according to the supposition of the spectaivr, behind some neighbouring buildings.

At Malmköping the meteor appeared to proceed from the northcrn heavens towards the west, leaving behind it a fine white streak, which was distinguishable for two minutes. At a height of $25^{\circ}$ above the horizon it disappeared without falling asunder. At Linkojping the nucleus of the meteor was pear-shaped, of blinding whiteness, followed by a streak of fire which was strongly luminous notwithstanding the clear bright sunshine, and about eight times longer than the nucleus. It was first observed pretty high up in the north-east, but afterwards sank to a height of $\mathrm{IO}^{\circ}$ above the horizon in the west, where it broke up without noise into a number of star-sparks. In Skara the meteor, followed by a beautifully luminous streak of fire, appeared to fall asunder, throwing out sparks strongly at the same time, after having gone from east to west with an apparent diameter of half that of the moon. In Hedemora two fire-balls were seen, one close behind the other, falling from the zenith towards the west, lexving behind them a light grey streak. A minute after the meteor passed from the field of view, a loud explosion was heard, which is also mentioned in reports from the town of Falun and from Gustafs and Stora Tuna parishes. In Mora no explosion was heard, but here the meteor, which left in its path a stream of fire of a deep violet colour, was seen to fall asunder in the south-southeast, with a strongly luminous fire rain, the fire diops of which, however, were extinguished before they reached the horizon. In Karlskoga a fireball of a blinding clear reddish white lustre was seen high up in the zenith. Hence it sank towards the northnorth-west to a height of $30^{\circ}$, and afterwards parted into three or four smaller pieces, which speedily went out and resembled the sturs which fall from a rocket. The meteor left behird it a white smoke, which in the calm air remained in the direction of the fall about a minute, and afterwards dispersed. In the neighbourhood of Karlstad, the meteor was thought to fall in the north east. It was compared to a falling star rocket. It was very bright, with a whte nucleus, having fire-red edges, and passing

x Abstract of an Address by Prof. Nordenskjöld at the Anniversary of the Royal Swedish Academy of Sciences. when bursting asunder to a blinding white, the separate pieces being clearly visible. Its apparent size was compared to that of the full moon, and after its disappearance a white streak remained for some seconds in the sky. In Hobiol parish in Dalsland there was seen in the sky a pointed fire-ball, resem. bling in form a socla-water llask, at first pretty high in the heavens, afterwaris approaching the earth, dividing into two parts and disappearing witbout any detonation after the lapse of half a minute. At I ysekil the meteor appeared to fall perpendicularly in the north-west, and spring as!nder without any noise some few feet above the surface of the water. According to a statement in the newspapers the moteor in question was simultaneously seen at Christiania, In Denmark and Finland it was not visible.

From a careful and critical examination of these statements, and many others which have been collected, it appears that the meteor in question, possibly with the neighbourhood of $\gamma$ Cephei as rudiation point, proceeded in a somewhat oblique direction to the place where the stones fell on the meteor bursting asunder. If with a point 40 kilometres south of Stialldalen as a centre, a circle be described through Christiania, the west. ernmost place where the phenomenon was observed, its circumference intersects Orust in the south, the neighbourhood of StockhoIm in the east, ond Gefle in the north-east, and includes all the places where the meteor was visible. At Stockholm, Hedemora, Karlskoga, and Lysekil, the meteor is said to have been visible first in the north-cast, somewhat bclow the zenith, and if the direction is noted where it disappeared in the neighbourhood of the horizon, this direction in general corresponds very well with the tirection from the place of observation to the place of fall. 'The meteor thus went under the horizon or disappeared in its neighbourhood at Stockholm to west, at Gefle to sonth-west, at Mora to souh-south-east, at lysekit to north, at Malmkiiping to north-west, and so on.

The meteor thus xeacher the end of its short luminous path in the region where the fall took place. It became luminous at a height which cannot, after making allowance for errors of observation, he reckoned at less than 300 to 400 kilometres, but was probably greater. At this height the atmosphere, notwithstanding its extreme tenuity, is capable by its resistance of heating red hot a body moving with cosmic speed, as of 75 litlometres per second, and if the composition of the atmosphere at this height be the same as at the surface of the earth the meteor will meet with sufficient oxygen to maintain a lively combustion of the combustible matters which enter into the composition of the metcor. It appears to me that we have here an explanation of the considerable height in the atmosphere at which meteors first become luminous - an explanation which is so much the more probable as we now not only know a number of carboniferous meteorites, but also by the meteorite fall at Hessle, in Upland, have distinct proof that the common meteorites may be accompanied, and perhaps are generally accompanied, by an easily combustible carbonilerous dust. Only through such a supposition can we obtain an explanation of the large size of these meteors when compared with the stones which fall, as well as of their strong illuminating power, which clearly shows that the light arises from the glowing of solid masses, and not merely from the compressed and heated gases which the meteor has collected before it.

The statements regarding the size of the Stitldalen meteor are very various. The most probable are those which give it a diameter of six minutes, which, supposing the distance to be 250 kilometres, would give the fireball a diameter of 436 metres, or nearly I, 500 feet. In comparison with this size the stones that have fallen are surprisingly small, which yields a further support to the supposition that the main mass of the meteor consisted of substances which had already high up in the air been dissipated in the form of gas or undergone combustion. In the case of the Ställdalen meteor there is also the exceedingly remarkable circumstance that the fireball was not visible in the region where tha path of the meteor struck the earth and where the meteorites fell, alchough this place lay nearly in the centre of the area where the meteor was visible as a luminous fireball, and although the sky here too was clear and cloudless with the exception of the little dark cloud which the meteor collected before it in its path through the air. It was probably this cloud which prevented it from being seen in the region which lay in the direction of the fall. Although no fireball was seen here, loud detonations were heard and some light streaks of cloud were visible in the zenith, from which, according to some, faint flashes of fire 
resembling lightning were seen dinting. Whistling, rumbling, and rattling noises were also heard. The sound was thought, for the most part, to come from the west or south-west. It was not heard in Karlskoga, which lies to the south, but far to the north and north-west. At Falun it was supposed that a fall of rock had taken place in a mine, and at Grandgrufvan, at Lud. vika, the sound was heard as of a peal of thunder at a depth of sixty metres underground. At other places a dynamite magazine was thought to have exploded, or it was taken for a loud clap of thunder.

In the neighbourhood of a workman who was culting trees in a wood several branches of a tree were broken off by a stone weighing nearly a kilogram, in a way which clearly showed no great falling velocity, which was further confirmed by the stone making a hole in the ground only a decimetre in depth. Another person saw a stone fall close beside him, and immediately took it up. It was not at ail warm. A girl saw a stone weighing two kilograms fall to the ground "so that the earth smoked." Several fell in the Lake Biorken or were picked up in the neighbourhood soon after. One weighing $8 \frac{1}{2}$ kilograms fell in a ryefield. In falling it had gone in two pieces and made an eightinch deep hole in the cultivated soil. The largest stone weighed $12 \frac{1}{s}$ kilograms.

The number of the stones that have been found, however, amounts only to eleven, with a total weight of thirty-four kilograms. They were scattered within an oval two kilometres bro:ad, whose larger axis had a length of eight kilometres. The largest stone was found in the south-west end of the oval, in a meadow surrounded by wood. It is probable that larger stones have fallen farther into the wook, and thus escaped observation. The stones are of very irregular form, and on their surface are full of the depressions peculiar to meteorites. On the surface they are, as usual, covered with a blackish fused crust of very variable thickness, being so thick on some of the fractured surfaces as to completely conceal the colour and inequalities of the main mass, and on other similar surfaces so thin that the colour and crystalline structure of the main mass may be clearly distinguished. Sometimes the crust is completely wanting, so that the surface of the stone, with the exception of an inconsiderable blackening, resembles a fresh fracture. stones are thus fragments which have been formed at different times, and exposed for different periods to the action of the glowing envelope. The largest stones are covered in many directions with black friction surfaces which are more clearly marked on these meteorites than on any I know. These too have probably been formed in our atmosphere, and show that with the great pressure produced by the resistance of the air, cracks have been formed in the meteorite along which its different parts before springing asunder rubbed against each other during the rotation of the irregularly-formed mass, whereby the uneven surfaces have been smoothened, and coloured black by the heat developed during friction, the projecting metallic particles flattened, \&c. On breaking in pieces the meteorites in question, they are found to consist of a coarse breccia-like mixture of grey and of nearly black portions, little differing from each other in chemical composition. It is remarkable that the grey mass when heated becomes dark, and thereby in appearance quite like the black, which appears to show that some of the breccia-like pieces found in the stones had been heated, while this does not appear to have been the case with the other part. Different pieces of the Stalldalen meteorites thus appear to have been exposed to the action of very different temperatures before they were united into the mass, hard, tough, and difficult to break up, which formed the meteorite.

'The stones that fell at Stailldalen have been carefully aralysed by Mr. G. Lindström, assistant in the mineralogical department of the Riks Museum, who found them to consist of nickel-iron; a silicate decomposed by acids, chiefly olivine; a silicate indecomposatle by acids, probably bronzite ; magnetic pyrites, and inconsiderable quantities of phosphide of nickel-iron ; of a phosphate, and of chloride of iron. The first-named substance, a metallic alloy of ninety per cent. iron and ten per cent. nickel, is not known fof terrestrial origin, but distinguishes most meteorites, and makes it possible to separate with certainty the meteorites which have fallen at Ställdalen from all other minerals occurring in the quarter. The two other main constituents again, olivine and bronzite, are also wanting in our granites, gneisses, and common slaty rocks, but are found commonly entering into the composition of a number of rocks which by most of the geologists and mineralogists of the present day are considered to be of plutonic origin. Many circumstances, however, indicate that these rocks, which in remarkably regular layers cover exten. sive regions of the earth's surface, oftert, but not alway's, consist of stratified tuff-like formations which during the enormous duration of geological periods have assumed a crystalline structure. The resemblance between them and various constituent parts of the meteorites is so striking that the question must be seriously and impartially discussed whether a part of the plutonic rocks are not of cosmic origin. By this $f$ mean that it gradually fell to the earth even after its surface formed an abode for animals and plants, and that under favourable circumstances it collected so as to form proper stratified so-called plutonic rucks, in which, through subsequent chemical changes, so great a development of heat has sometimes taken place that volcanic and plutonic incandescent craters have arisen in the interior of the earth.

Many observed facts may be quoted in support of this view, if it for the present appears very strange on account of the great changes it would bring about in the prevaijing ideas of the history of the formation of the heavenly body which we inhabit. We have perhaps here the true solution of the many disputed questions raised by the discovery of meteoric iron at Ovifak, in Greenland, a simple explanation of the abundant occurrence of magnesia in certain geological formations, and of many other geological phenomena difficult of explanation according to theories now prevalent.

\section{UNIVERSITY AND EDUCATIONAL INTELLIGENCE}

Campringe.-Mr. W. N. Shaw, B. A., Emmanuel College, I6th Wrangler, 1876, and Ist Class Nattiral Sciences Tripos (Distinguished in Physics), I \&76, has been elected to a fellow. ship in his College.

LONDON.-The following have passed the recent examination for the degree of Doctor of Science in the branclies specifed :-

Iranch IV.-Inorganic Chemistry.-J. M. I. . Munro, Royal College of Science, Dublin.

Branch VI.-Electricity (treated experimentally).-O. J. Lodge, University College.

Branch VIII,-Physical Optics, Heat, Acoustics (treated mathematically).-J. F. Main, Trinity College, Cambridge.

Branch X. - Comparative Anatomy.-A. M. Marshall, B.A, St. John's, Cambridge, and St. Bartholomew's Hospital.

Branch XIV.-Geology. - W. Saise, Royal School of Mines.

\section{SOCIETIES AND ACADEMIES}

\section{LONDON}

Geological Society, June[20.-Prof. P. Martin Duncan, F.R.S., president, in the chair.-Messrs. George Alexander Gibson, Henry P. Gurney, John Higson, and Francis Stevenson, were elected fellows of the Society.-The following papers were read :-On a hitherto unnoticed circumstance affecting the piling up of volcanic cones, by R. Mallet, F.R.S. - The steppes of Southern Russia, by Thomas Belt, F.G.S. -The glacial period, by J. F. Campbell, F.G.S. - The action of coast-ice on an oscillating area, by Prof. John Milne, F.G.S., of the Imperial College of Engineering, Tokio, Japan.-On points of similarity between zeolitic and siliceous incrustations of recent formation by thermal springs and those observed in amygdaloid and other altered volcanic rocks, by Prof. A. Daubrée, F.M.G.S.-On the cretaceous Dentaliadæ, by J. S. Gardner, F.G.S.-On a number of new sections around the estuary of the Dee which exhibit phenomena having an important bearing on the origin of boulder-clay and the sequence of glacial events, by $D$. Mackintosh, F.G.S.-Discovery of silurian beds in Teesdale, by W. Gunn, F.G.S., and C. T. Clough, F.G.S., of H.M. Geological Survey.-On the superficial geology of British Columbia, by George Mercer Dawson, F.G.S., Assoc. R.S.M., of the Geological Survey of Canada.-The exploration of the ossiferous deposit at Windy Knoll, Castleton, Derbyshire, by Rooke Pennington, F.G.S., and Prof. W. Boyd Dawkins, by Prof. W. Boyd Dawkins, F.R.S.-Description of the fossil organic remains from Bendigo, by M. Carl August Zacharix, communicated by the president.- Notes on some recent discoveries of copper ore in Nova Scotia, by Edwin Gilpin, F.G.S. -Glacial drift in the North-eastern Carpathians, by R. L. Jack, F.G.S., and John Horne, F.G.S., of the Geological Survey of 